\title{
HUMAN RESOURCE MANAGEMENT INFLUENCE ON EMPLOYEE RELATIONS IN AFRICA: CASE OF BOTSWANA PUBLIC SERVICE SECTOR
}

\author{
Theophilus TSHUKUDU*
}

\begin{abstract}
This paper endeavour to investigate the influence of Human resource Management as a function in the promotion of effective labour relations in the Botswana Public Sector setting. Principle to the interface between management and employee relations is the mediatory role that requires a sound professional and unbiased human resource management practices. Human Resource Management (HRM) is an umbrella term used to describe the management and improvement of employees in an organization. HRM remains pivotal to the employee relations in an organisation including the public sector environment. Human resource as function facilitate a positive relationship between employees and hence have a very big influence on the whole performance of the organization. Although HRM is key to the performance of organizations in the sense that it brings employees together, employee and employer and the whole professional and otherwise development of the staff as well as the company, little is still known about how HRM contributes to ER and productivity. (Raeder, 2014), said until now very little is known about how HRM practices influence ER and the details of how that influence increases productivity.

Keywords: Human Resource Management (HRM); Employee Relations (ER); Public service sector
\end{abstract}

DOI: 53373 / REDS.2021.53.4.053

\section{INTRODUCTION}

The main theoretical approaches to understanding the influence of Human Resource Management (HRM) on organizational results have focused on Human Resource Management practices as drivers of performance and competitiveness. The success and failure of an organization is caused by the relationship shared among the employees. The employees must have a good relationship amongst themselves otherwise they would always end up fighting with each other. Trust is the key factor between employees and the employer. The employer need to trust his employees to expect the best out of them. Trust occurs when one is comfortable with the other people. Employees together can come out with innovative ideas by discussing things among themselves and accomplish the task at much faster rate.

Employee relations is the study of relationship interaction of an employee to other employees and employee to an employer in an organization. This employees can choose to join any trade unions of their choices or choose not to join any trade

* Department of Management, Faculty of Business, University of Botswana. 
union. For an organization to perform very well in the market it has to have employees that have good relationship to each other and also their employer must value them. The employer or an organization should value its employees so that they can work together in a good and nice way to meet the organization's goals. A human resource professional plays a key role in bringing the employees together. Human resource professional undertake certain activities which help in strengthening the bond among the employees and bring them closer so that the relationship can be of good standards. The people taking care of the Human Resource Management activities plays a major key role in involving all the employees into productive activities which would give them an opportunity to know each other well.

Human resource is the people working in an organization and the organization take this people (HUMAN RESOURCE MANAGEMENT) its assets that help the organization with their skills, knowledge and abilities so that the organization can run its day to day activities and meet its set goals and targets so that it can compete with other organizations in the market or to have a competitive advantage over its competitors. Therefore organizations expect employees to be collaborative, innovative and committed to their work and yield good or better results. In other words the employer needs employees who can go an extra mile in performing tasks given and who are multiskilled can be multi tasked. Also there is a belief that Human Resource Management is all about recruiting, hiring and firing, but Human Resource Management contribute to success and failure of the organization as it builds the relationship between the employer and employees and also between an employee and other employees. Therefore Human Resource Management brings the employer and the employee together and it also bring employees together by not taking any sides or by not favouring anyone. The employer and the employee should be given equal treatment by Human Resource Management officers. The Human Resource Management make sure that employees feel engaged in their work which makes them feel they contribute to the mandate of an organization. Human Resource Management encourage productivity, also motivate employees and make sure they have high morale.

In other organizations the Human Resource Management has two primary functions. Firstly the Human Resource Management prevent or resolve problems and disputes between employees and management. Secondly the Human Resource Management create and enforce policies that are fair and constant for everyone in a workplace.

\section{BACKGROUND STUDY}

Employee relations has representative laced industrial relations because the term for outlining the connection between employers and employees. Today, employee relations is seen as that specialize in both individual and collective relationships within the workplace, with an increasing emphasis on helping line managers establish trust-based relationships with employees. A positive climate of employee 
relations with high levels of employee involvement, commitment and engagement can improve business outcomes likewise as contribute to employees' well-being. In the past most of the organizations more especially department didn't value employees. There was no HR division but instead there was Personnel management. In a company, Human Resource is more concerned with the welfare of the workers and also treat them as assets of a company whereas Personnel management didn't consider employees as assets of organization. Personnel management was more into hiring and firing of employees. The connection between the employer and employees wasn't amicably because the employer was the one who makes decisions without consulting employee and also the employers' words were final. Both the employer and also the employee felt intimidated because employees most of the time engage the trade unions in every issue the have with the employer because the connection between the worker and also the employer didn't allow the worker to possess a say with the employer. The introduction of Human Resource had a positive impact in many organizations because if conflicts arise between employee and other employees or between employee and employer they'll be resolved amicably before they become grievances or disputes.

\section{PROBlem Statement}

The role of human resource management and its influence on employee relations was considered to be a threat in most organizations, this was because of the result of being resistant to change as they had to change from personnel management to human resource management. As most organizations are getting civilised and getting to appreciate human resource as a key factor in efficient and effective service provision, HRM has become universal overtime. Nonetheless very little is still known about how HRM influences productivity and most of the companies don't adhere to its procedures especially when we look at the Botswana's context.

\section{AIM OF STUDY}

The aim of this research is to find out the roles of Human Resource Management and its influence in employee relations.

\section{OBJECTIVES}

- The goal of this study is to find out the role of human resource management in employee relations. For an organization to excel and perform well, the relationship between the employer and the employees should be satisfactory as they are the backbone of every organization. The study is going to find out the average role of human resource managers and how their contribution in an organization influence how employees relate towards one another. Therefore the objectives of this paper are; - 
- To outline the existing procedures that are being practiced in the human resource section and if those are practiced accordingly.

- To identify issues that are faced by employees arising from the lack of proper compliance of human resource processes.

- To propose suitable solutions in terms of human resource practices that will improve how employees relate to each other.

\section{RESEARCH QUESTIONS}

The following are research questions that are to be addressed on this study;-

- Are there existing procedures practiced in the human resource section?

- Are organizations complying with the existing HR procedures?

- What HR challenges face by employees due to lack of compliance to HR procedures?

- What are the possible solutions to the HR challenges faced by employees due to lack of compliance?

\section{LITERATURE REVIEW}

According to Armstrong and Taylor (2014), a strong Human Resource Management system facilitates a collective interpretation of Human Resource Management (HRM) practices in a common direction, and consequently, a conjoint response by employees. The Human Resource Management is encompassing the dimensions of distinctiveness, consistency and consensus for it to be of a system that is strong. Human Resource Management departments design practices that configure the Human Resource Management system to be implemented within organizations. The strength of the Human Resource Management system could mean that the area of Human Resource works well, has credibility, and is valued by employees and other organizational units. In that sense it can be related to the notion of perceived organizational competence, which means that employees have trust in the organization's ability to achieve its goals and objectives. Individuals who perceive that their organizations have a high level of organizational competence may feel that several of their socio-emotional needs are being met, such as the need for esteem, a sense of belonging or the need for emotional support, which feeds into employee commitment.

When it comes to employee relations, Human Resource Management department has two primary functions. First Human Resource Management helps to prevent and resolve problems between employees and their managers and also between employee and another employee. Secondly Human Resource Management help in creating and enforcing policies that are fair and consistent for everyone in the workplace. Workplace conflicts happen everywhere everyday but the role of Human 
Resource Management is to manage them with extra care. Human Resource Management professionals tackle problems before or after a conflict turns into a face-off between departments that refuses to work together or a screening match between employees. Conflicts at workplace is actually normal and healthy, and culture where conflicts are ploughed can spur innovation, diversity of thoughts and better decision making therefore Human Resource Management should handle conflicts with extra care and find out what really transpired between the two parties to hear all sides of the story. Human Resource Management assist in creating and enforcing policies that are fair and consistent for everyone in the workplace in order to ensure compliance with laws and regulations, give guidance for decision making and streamline internal processes.

A human resource professional plays a key role in binding the staff together. HR professional must undertake certain activities which help in strengthening the bond among the staff and convey them closer. Human Resource Management should encourage social interaction between employees. At large organizations employees come to figure daily, add the identical offices but hardly talk over with one another. Individuals are so engrossed in their daily routine work that they hardly get time to interact with one another. Many of them don't even know the complete names of the person sitting next to their workstations. Even during their lunch break they wear away their respective desks busy scrolling their phones without rebuke other employees. To confirm that employees don't remain strangers, human resource department must make sure that several group activities are being organized at the workplace to bring all employees on a typical platform. Research says that if the staff are satisfied with their job responsibilities, they have a tendency to stay happy and avoid conflicts with one another. Individuals develop a sense of trust and loyalty towards their organization and doesn't waste their time and energy in unproductive tasks.

Human Resource managers should come up with activities like; Human Resource Management should organize team-lunch and activities which are of great opportunity for workers to network so they might get to grasp one another fine and have trust on them because trust may be a key to an honest relationship between employees and their employers. They must also organize various activities like potlucks and tiny get together at the workplace. Ask everyone to bring some dish in keeping with his taste and convenience. Let the staff enjoy together.

Employees tend to debate lot of the many things except routine add these styles of informal get together. Also one day in every last day of the times probably the Day of Judgment of the month should be earmarked with the only real objective of celebrating birthdays falling within the particular month. As an example all those born within the month of January should celebrate their birthdays together on the Day of Judgment of the month which is 31 st of January which is able to help a good deal for them to stay charged for next one year. The HR should send a proper mail inviting all. Let everyone enjoy and commemorate. Divide individuals into groups and task each group with a tiny low activity to try to do. One group can probably be tasked to embellish the venue whereas the opposite group is given the responsibility 
to arrange the cake yet as other eatables so on. The HR person should ideally support each group to confirm that nobody faces any difficulty in getting things organized.

The human resources team is additionally responsible to prepare various events like sports day, annual day, green day etc. the staff must be encouraged to participate in these types of extra-curricular activities. Employees are able to relax this manner and take a chance from their routine work. Problems take place when the work tends to become monotonous. Employees should enjoy coming to office instead of treating work as a burden to them. The HR in coordination with the team leaders must display the names of the highest performers each month on the company's noticeboard. Send a congratulations mail further. The human resource professional together with the supervisor can even reach a tiny low trophy as a token of appreciation to the highest performers. Try this activity within the presence of all. The one who has performed well starts trusting his management more and strives hard to win more trophies within the future. Most are privy to each other's performance and gets inspired further.

While making the organization's policies, the human resource department must fix a typical time for lunch for all the staff. HR department should assign hour lunch time for the identical and confirm that nobody during that lunch time is seen engaging at their workstations. Everyone should close at the office canteen and take lunch together. When people sit together, a number of their problems disappear on their own. Employees share their sorrows, displeasures and various other problems with their colleagues and this manner come closer to every other. People develop better bonding this manner. A relaxed environment can build a robust bond and therefore the relationship between employees at workplace and even between employees and their managers. A number of employees in a corporation think that Human Resource Management will always side with the management. This is often not always true, but the assumption isn't challenged because Human Resource Management doesn't do enough to manage their public representative. When a replacement employee joins a corporation, the HR managers confirm that the new employee receives a warm welcome by all members of the staff. The induction program should be conducted at the room so every employee are often invited. Because the HR manager, with respect, ask the new employee to introduce himself well. Inform others know that a replacement member has stepped into their family to assist them in their assignments.

The HR together with the road managers must communicate the key responsibility areas clearly to the staff to extract the simplest out of them and avoid dissatisfactions later. Human Resource Management function provides guidance and training and will develop and help to introduce and maintain formal processes, but it does not do line managers' job. Human Resource Management practitioners may deal directly with the trade unions and their representatives. They are also likely to have a measure of responsibility for maintaining participation and involvement processes and for managing employee communications. Human Resource 
Management function can and should play a major part in developing employee relations strategies and policies that aim to;

- Achieve satisfactory employment relationships, taking particular account of the importance of psychological contracts.

- Build stable and cooperative relationships with employees which recognize that they are stakeholders in the organization and minimize conflict.

- Achieve commitment through employee involvement and communications processes.

- Develop mutuality- a common interest in achieving the organization's goals through the development of organizational cultures based on shared values between management and employees.

- Clarify industrial relations processes with the trade unions and build harmonious relationship with them on the partnership basis.

\section{FIVE EFFECTIVE WAYS TO IMPROVE EMPLOYEE RELATIONS}

- ASK FOR INPUT- Having good employed relations requires you to have a strong discussion with your team as an employer. Including them in a strategic decisions and getting their input will not only increase relations, it can also provide you with new sights and help you look things from a different perception.

- COMMUNICATING THE COMPANY MISSION AND VISIONEmployee want to know what they are working towards, They also want to understand how their specific role fits in with the company's strategic direction. Make sure to communicate the company's mission and vision, and be transparent about company direction as the employer so that the company mission and vision are achieved.

- RECOGNIZE A JOB WELL DONE- A simple "thank you" and a hand shake for well-done can go a long way. Taking the time to recognize your employees' efforts on a regular basis will help keep them engaged, and they will be more open to working with and communicating with management not working against them.

- PROMOTE WORK-LIFE BALANCE- Work-life balance matters and it is becoming an increasing concern for your employees creating a work environment that promotes Work-life balance and gives your employees the flexibility to balance both aspects of their life will improve relations and ultimately create a robust team.

- OFFER CAREER DEVELOPMENT OPPORTUNITIES - As an employer, your employees does not want to be stuck in the same role forever. They want to work for companies that provide them with a clear career path and career development opportunities. When employees are offered chances to have carrier development, they get motivated and this lead to a good relationship at workplace. 


\subsection{Role of human resource in employee relationship management}

Yes it is very true that Human resource management plays an important role in building strong employee relationships in an organization by conducting activities which allow employees to work with each other as well as managers. Human Resource professionals can improve relationships between co-workers and also between the manager and the employees at work place.

\subsubsection{Relationships between co-workers}

Peer relationships, if taken care of and managed properly, it can significantly improve organization's culture. A good relationship builds camaraderie and boosts morale. When teams co-operate, employees can learn new skills from each other, motivate each other and collaborate. Such a healthy environment encourages employees to perform and achieve their goals.

The following are ways HR can improve coworkers' relationships-:

$>$ BUILD CROSS-FUNCTIONAL TEAMS (CFTs)

Cross-functional teams span across organizational boundaries. CFTs allow employees from different departments to return together, combine their skills and work towards a standard goal. Building such teams can allow people from diverse departments who have never worked together to get to know each other. Moreover, when people with different skills work on a project together, problem-solving becomes efficient. When you club together people that are experts in several domains, new and innovative ideas will emerge. When people work together, they can let go of their presumptions and understand each other's perspectives. It allows them to see how their team members arrive at a conclusion and their thought process. It makes them more understanding and accepting of each other. (Related: the increase and Importance of Cross Functional Teams).

\section{$>$ CONDUCT TEAM BUILDING ACTIVITIES}

The benefits of conducting team building activities are endless. It makes communication among employees more frequent, improves problem-solving and decision-making skills. Most importantly, team building activities build and strengthen relationships. When teams collaborate, it paves the way for trust to be built, exchange ideas and opinions. Mostly, it is about sharing and combining knowledge and experience to reach goals.

\section{$>$ EQUIP THEM WITH COMMUNICATION TOOLS}

For relationships to form and sustain, employees need to communicate with each other. Lack of communication can cause misunderstandings and as a result, give rise to conflicts. With the influence and immediacy of technology in the present age, the need to always stay connected is paramount. Workplaces too need to equip themselves similarly. Empowering employees with communication tools may be a good way to make sure that employees can always share important information with 
one another. Cloud-based messaging tools like Skype, Slack allow people to share messages, pictures and files from anywhere around the world at any time. Therefore, with new-age communication tools, you'll effectively strengthen relationships between your remote workers too.

\subsubsection{The relationships between the manager and the employee}

Employees think twice before sharing information with their managers because they're always worried about how it is going to reflect on their performance review. But managers who can merge the gap between them and their employees without being too friendly or too authoritative will build lasting relationships with their employees.

The following are ways HR can improve the manager and the employee relationships-:

\section{CONDUCT SURVEYS TO UNDERSTAND HOW EMPLOYEES FEEL}

Working in an industry, sometimes executives complaining about how their employees are not engaged, their turnover is too high and so on. But instead of trying to find out why the employees are not satisfied, companies try to load them with meaningless information. You might be providing employees with great insurance plans that they do not really need, but maybe what they really want is a work from home policy. The only way to know this is by conducting surveys. Surveys like engagement surveys, 360-degree surveys enable the organization to understand the needs of the employees. Once you know where you are lacking, you can work on rectifying and providing feasible solutions to your employees. The results of holding these surveys are going to be that you simply workforce will feel that you genuinely care about their needs and requirements. This will build trust, loyalty, improve your branding and strengthen the general relationship you've got together with your employees.

\section{HAND}

> TRANSPARENCY AND INVOLVEMENT MUST GO HAND-IN-

One of the worst things you can do as a manager is keeping your employees in the dark. Just like your partner, your employees will never have a trusting relationship with you if they feel you are hiding things from them. Therefore, always be clear and transparent with your actions and the decisions you make. Let everyone know what is going on in the company, what changes have been adopted, how much the company makes and so on. Another vital pointer for your employee relationship management is involving employees. When you favor a handful of employees, share information only with them and try to include them in all decision making processes, others take notice. And it is only natural that they feel offended by it. Therefore, to take care of a good and unbiased work environment, include everyone in your discussions. Give everyone the opportunity to share their ideas and express their opinions. 


\subsection{The role of employee relations manager in HRM}

As a branch of HR management, employee relations managers look out for the simplest interests of employees and assist employers with contract disputes and negotiations. The following are roles of employee relation in HRM-:

$>$ CONSULT ON NEW AND EXISTING POLICIES

The policies that an organization has in place determines the way employees can act. Most organizations have sexual harassment laws for example, that forbid employees from treating others in a negative way because of gender or sexual orientation. Employee relations managers are those liable for setting new policies and ensuring that each one workers follow those policies. In addition to policies concerning harassment, you'll create policies and programs regarding drug or alcohol use, the way employees act on social networking sites and the way they act around clients.

$>$ ACT AS A UNION REPRESENTATIVE

Depending on the industry you work in, you may need to act as a union representative on the job. Unions provide job stability and security to workers who pay annual dues. If a problem arises, a representative from the union will meet with representatives from the company to determine what to do next. You may work as a representative for that union or meet with one of those representatives on behalf of your employer. The union will want to know that your company followed all the standards it put in place and that workers did not violate any laws.

\section{$>$ COMPLY WITH ALL LAWS}

The Society for Human Resource Management created a template that employee relations managers can follow when creating a resume and applying for a replacement job. The SHRM includes one duty that those managers perform as complying with all federal, state and native laws concerning employment. Those laws include not discriminating against potential applicants on the basis of factors like race or age, ensuing that employers follow all OSHA standards and providing employees with a safe place to debate problems they experienced on the work.

Employee relations jobs share some similarities with human resource jobs. The main difference is that employee relations specialists' focus more on the workers than on the corporate as an entire. Some of the functions of an employee relations manager include complying with all laws, negotiating contracts, consulting on all new policies and dealing with the union. Any well-maintained organisation must aim to inaugurate their company from both inside and out of doors forces. They should also align both inside and out of doors power so as to extend and achieve expected goals. To do this, both the industrial relations and human resource management should come into play. Industrial relations and human resource management are two departments that relate to each other but hold different roles within an organisation. They are also divided under a different concept. 


\subsection{The different concepts}

\subsubsection{Industrial relations}

Industrial relations (IR) or commonly known as employment relations examines various employment situations that include employees, employers, trade unions, and government. Initially, IR will begin with employment relations where compensation is obtainable in exchange for work like employment agreement. IR is additionally suffering from a choice of manager and employer.

\subsubsection{Human resource management}

Human resource management (HRM) is simply about managing human resources within an organisation. They should specialise in achieving organisational goals and objectives like increased ROI through hiring best talents. HRM also provides support and development to motivate workforce. Thus, effective management of human resources can directly contribute to organisational effectiveness.

\subsection{The different responsibilities of IR managers and HR managers}

TABLE 1. THE IR MANAGERS AND HR MANAGER'S RESPONSIBILITIES. HUMAN RESOURCE MANAGEMENT RESPONSIBILITIES

Keeping and maintaining employees to achieve organizational goals.

$>$ Creating a positive and friendly work environment.

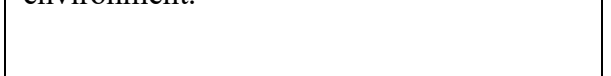

$>$ Providing employees with an organisational structure so that they can work effectively.

$>$ Creating job opportunities that align with the organization's vision, mission and values.

$>$ Provide fair treatment and pleasant working conditions to employees.

\section{INDUSTRIAL RELATIONS RESPONSIBILITIUES}

$>$ Reduces disputes that directly affect productivity.

$>$ Promote economic growth and
development based on employee performance and employer leadership skills. accepted rules and procedures.

$>$ Ensuring a smooth flow of business operations.

$>$ Boost the morale of employees with peaceful and save environment. 


\section{DISCUSSIONS}

Human resource Management is very important function in an organisation. Without Human resource management companies or organisations would not be able to effectively recruit and retain employees, and they wouldn't be able to maintain a healthy, accepting workplace culture and environment. According to Mohammed Shameen-UI-Ahson, Feb 3.2017, an effective Human Resource Management system allows organisations to address human resource issues strategically. This helps the workforce provide high quality health services, despite internal and external challenges to the organisation. Human resource management play an important role for organisation to manage employees to work effective, creative, quality and productivity to reach the competitive advantages over competitor and achieve organisational goals and objectives. So if organisation that have not considered effective of Human Resources Management they will not manage their staff at work effectively and cannot examine what they will do to make working people more productive and effective. Human resource management practices help to insure the legal compliance which is a key for the long term survival of an organisation. All in all we can say Human Resource Management is very crucial for organisation, without it the organisation cannot reach its goal and objectives.

\section{RECOMMENDATIONS}

The crucial role that human resource managers should play in the day-to-day operation of the organizations is to bring cooperation amongst employees. Accordingly, being a friendly and caring boss would result in a relaxed working atmosphere that will be uncluttered by formalities and social rituals. Good communications is crucial to the smooth and effective operation of both the small and large organizations. To deal with work related complaints and grievances, manager should resort to informal discussions or meetings, the environment should not always be formal as some of the issues can be misinterpreted and therefore become easily to be resolved. These could take place during normal working hours, at lunch time, or after work. Most often, however, the setting of this type of discussion or meeting should be deliberately chosen by the manager to include the surroundings that they are familiar to the respective employees.

\section{CONCLUSIONS}

The attempts by HR managers to instigate internalization of employees' and community objectives by the management and develop policies and practices which address several employee roles reflect this acknowledgment of plurality. Human 
Resource Management remains pivotal for the performance of all organizations. As define above HRM is a process of recruiting, selecting, inducting employees, providing orientation, taking employees through training and developing them, appraising the performance of employees, deciding compensation and providing benefits, motivating employees, maintaining proper relations with employees and their trade. Because of its comprehensive approach, HRM has been seen to have an outstanding influence on Employee Relations and on the organization as a whole.

\section{REFERENCES:}

- Absar, M. M. N., Nimalathasan, B., \& Jilani, M. M. A. K. (2010). Impact of HR practices on organizational performance in Bangladesh. International Journal of Business Insights and Transformation, 3(2), 15-19.

- Adisa, T.A., Osabutey, E.L.C. and Gbadamosi, G. (2016), "Understanding the causes and consequences of work-family conflict: an exploratory study of Nigerian employee", Employee Relations, Vol. 38 No. 5, pp. 770-788.

- Armstrong, M. (2011), Armstrong's Handbook of Human Resource Management Practice, 12th ed., Kogan Page, London.

- Armstrong, M. and Taylor, S. (2014), Armstrong's Handbook of Human Resource Management Practice, Kogan Page Publishers.

- Arrowsmith, J. and Parker, J. (2013), "The meaning of 'employee engagement' for the values and roles of the HRM function", International Journal of Human Resource Management, Vol. 24 No. 14, pp. 2692-2712.

- Gilbert, C., De Winne, S. and Sels, L. (2015), "Strong HRM processes and line managers' effective HRM implementation: a balanced view", Human Resource Management Journal, Vol. 25 No. 4, pp. 600-616.

- https://blog.vantagecircle.com/employee-relationship-management accessed at 12:00 on the

- https://www.hrinasia.com/employee-relations/industrial-relations-vs-human-resourcemanagement/ accessed at 12:00 on the 24-04-2020

- https://www.humanresourcesmba.net/lists/5-functions-of-an-employee-relations-manager/n accessed at 12:00 on the 24-04-2020

- https://www.managementstudyguide.com/role-of-hr-in-employee-relationship.htm accessed at $11: 45$ on the $24-04-2020$

- https://www.managementstudyguide.com/role-of-managers-in-employee-relations.htm accessed at 11:50 on the 24-04-2020

- Kramar, R. (2014), "Beyond strategic human resource management: is sustainable human resource management the next approach?" International Journal of Human Resource Management, Vol. 25 No. 8, pp. 1069-1089.

- Noe, A. R. Hollenbeck, R.J. Gerhart, B. and Wright, M. P. (2019) Human Resource Management- Gaining a Competitive Advantage (11 th edition), McGraw Hill Education, 2Penn Plaza, New York.

- Podgorodnichenko, N., Edgar, F. and McAndrew, I. (2019), "The role of HRM in developing sustainable organizations: contemporary challenges and contradictions", Human Resource Management Review, in press, doi: 10.1016/j.hrmr.2019.04.001.

- Raubenheimer, K. and Rasmussen, E. (2013), "Employee-focused corporate social responsibility in practice: insights from managers in the New Zealand and Australian financial sector", New Zealand Journal of Employment Relations, Vol. 38 No. 3, pp. 35-56.

- Ryu, S. and Kim, S. (2013), "First line managers' HR involvement and HR effectiveness: the case of South Korea", Human Resource Management, Vol. 52 No. 6, pp. 947-966. 
- Schuler, R.S. and Jackson, S.E. (2014), "Human resource management and organizational effectiveness: yesterday and today", Journal of Organizational Effectiveness: People and Performance, Vol. 1 No. 1, pp. 35-55.

- Trullen, J., Stirpe, L., Bonache, J. and Valverde, M. (2016), "The HR department's contribution to line managers' effective implementation of HR practices", Human Resource Management Journal, Vol. 26 No. 4, pp. 449-470.

- Woodrow, C. and Guest, D.E. (2014), "When good HR gets bad results: exploring the challenge of HR implementation in the case of workplace bullying", Human Resource Management Journal, Vol. 24 No. 1, pp. 38-56.

-Wright, P.M. and Nishii, L.H. (2013), "Strategic HRM and organizational behavior: integrating multiple levels of analysis", in Paauwe, J., Guest, D.E. and Wright, P.M. (Eds), HRM \& Performance: Achievements \& Challenges, John Wiley \& Sons Ltd, Chichester, pp. 97-110. 